\title{
Perception and Evaluation of Noise Tempted Health Hazards and Risk Assessment from Portable Power Generators Usage in the Resident of Karachi, Pakistan
}

\author{
Akhtar Shareef ${ }^{*}$, Durdana Rais Hashmi \\ Centre for Environmental Studies, PCSIR Laboratories Complex, Karachi, Pakistan \\ Email address: \\ akhtarshareef@yahoo.com (A. Shareef) \\ ${ }^{*}$ Corresponding author \\ To cite this article: \\ Akhtar Shareef, Durdana Rais Hashmi. Perception and Evaluation of Noise Tempted Health Hazards and Risk Assessment from Portable \\ Power Generators Usage in the Resident of Karachi, Pakistan. Journal of Health and Environmental Research. \\ Vol. 7, No. 1, 2021, pp. 6-12. doi: 10.11648/j.jher.20210701.13
}

Received: December 30, 2020; Accepted: January 18, 2021; Published: February 2, 2021

\begin{abstract}
The aim of this study was to estimate the noise pollution level and possible health impacts due to the use of portable electricity generators in commercial areas of Karachi, city. 04 locations were selected at Tibet Centre, Empress Market, Garden Road and Saddar GPO Area. This study was designed to assess the perception and knowledge of power generator users towards the noise induced health hazards. A survey was conducted with 312 persons, randomly selected as shopkeepers, office workers and push-carters who participated as respondents in semi-structured questionnaire interview method. The questionnaire was divided into three sections as a) demographic characteristics include age, sex and educational level b) Knowledge and perception of noise pollution hazards and c) noise induced health hazards by the use of portable generators. Participants on the basis of their responses were categorized into four classes, no education / illiterate, SSC, HSC and graduate \& above level education. It was established that higher the educational level the respondents had, the more they were likely to be aware of health effects of noise pollution. Results showed that residents are in constant exposure of generator noise show adverse health effect on the habitants which includes hearing impairment, interference with spoken communication, sleep disturbances, cardiovascular disturbances, impaired task performance and negative social behavior and annoyance reactions.
\end{abstract}

Keywords: Portable Generators, Perception, Noise Pollution, Commercial Areas, Loss of Hearing

\section{Introduction}

According to the World Health Organization noise pollution is standing at third position after water and air pollution. Noise pollution problem is becoming a universal issue in developing countries. It is one of the prime environmental pollutants that has direct effects on human performance [1]. Noise is now considering an important factor for public health problems [2]. Exposure to noise pollution causes harmful effects on neuroendocrine system and detrimental effects on cardiovascular, cardiopulmonary and digestive systems. Chronic exposure to noise pollution is main causes of fatigue and interferes with concentration and reducing the efficiency of work [3]. Research study by Esther and Victor [4] regarding the "Impact of Noise Pollution on
Human Cardiovascular System" revealed that apart from Noise Induced Hearing Loss (NIHL), exposure to continuous or high levels of noise can cause several adverse health effects on cardiovascular system. According to the recent researches exposure to noise pollution can causes harmful effects on human health as Hearing Impairment, Negative Social Behavior and Annoyance, Interference with Spoken Communication, Sleep Disturbances, Cardiovascular Disturbances and Disturbances in Mental Health [5].

Noise pollution allied with portable electricity power generators is an emerging environmental issue in many developing countries [6]. The erratic supply of none or low voltage electricity by Power Holding Company in Karachi makes it imperative for individuals, companies and factories to generate the needed electricity through portable generators 
without considering its attendants effects $[7 \& 8]$. A portable power generator is a gasoline, petrol or diesel-powered device that is used as an alternative temporary arrangement of electrical power supply up to certain voltage [9]. Portable power generators are used very commonly in shops, offices and homes as an alternative source of power supply during power shutdowns period [10 \& 11]. These generators emit very high levels of noise, in addition to noxious air pollutant emissions. The noise from portable power generators may be generated by aerodynamic effects or due to forces that result from combustion process or may result from mechanical excitation by rotating or reciprocating engine components [12].

Noise is defined as loudness (intensity) and pitch (frequency) and the level of noise measured by using a logarithmic scale as decibel (dB) [13]. Recent researches show that noise pollution is now becoming a serious health hazards in our modern societies [14]. Prevalence of both auditory and non-auditory effects is widespread among the workers/operators working in a noisy environment. The nonauditory hazards of noise include: irritation, anger, loss of memory and sleeping disorders [15]. World Health Organization (WHO) estimated that 360 million peoples in the world disabling the hearing loss, out of which $91 \%$ are adults and only $9 \%$ are children [16]. Incidence of disabling hearing impairment in South East Asia is $2.4 \%$ in children; $9.5 \%$ in adults below 65 years and up to $48 \%$ in adults above the age of 65 [17]. The most common etiological factor for this age related deafness is noise pollution. National Institute on Deafness and Other Communication Disorders estimates that $15 \%$ of the population has got decreased hearing intensity due to loud noise that may be noise at work, leisure activity or use of mobile phone only [18].

\section{Materials and Methods}

This study was conducted in commercial areas of Saddar town in Karachi, Pakistan. Saddar town is the central part of Karachi that is the central business district and surrounded by commercial activities with high traffic density and parking places. 04 locations like Tibet Centre, Empress Market, Garden Road and Saddar GPO (General Post Office) area were selected for this study. All the selected locations were surrounded by different types of shops, offices and push carts. A comparative cross sectional study design was used which involved questionnaire to the participants / generator users in the selected areas of the city. The questionnaire assessed a cross-section of different age groups, sex, educational levels/ literacy level and occupation of respondents. The analysis has been carried out with the help of percentages and cross-classifications effects of noise, in terms of age as well as sex. The general population who had participated in this study included small business shops keepers, office workers, loaders and push carters above 16 years of age in all the selected areas and categories. The total sampling technique, i.e., maximized expediency sample, was employed. There were 310 respondents / participants, from
Tibet Centre $(n=90)$, Empress Market $(n=103)$, Garden Road $(n=50)$ and from Saddar GPO Area $(n=67)$.

A semi-structured questionnaire was used to gain information on the perception and knowledge from the participants regarding the hazardous effects associated with power generator noise. The questionnaire was divided into three sections. First section asked some general questions, such as age, sex, occupation and educational status. The following section of the questionnaire incorporated the questions on the status of Knowledge / Information about hazards of power generators Use. In the last section of the questionnaire, asked the questions to examine the risk / hazards with the exposure of generator noise on human health. Each questionnaire was reviewed carefully for appropriateness of respondent responses. Several discussions were held among the researchers who found certain anomalies regarding the ordering of questions and then felt the necessity of adding few more questions with changes and adjustments in the questionnaire. With some addition and correction, the questionnaire was finalized for testing. Both open and close-ended questions were also incorporated in the questionnaire. Field investigation has been carried out during the year 2016. Frequency distribution figures with percentage are provided to describe responses.

\section{Results}

Figure 1 presented the percentage of the respondents according to their age limit, showing that all the participants found between 16 to 59 years age, of which $267(86.1 \%)$ of the respondents were above 20 years whereas 43 (14\%) were below 20 years of age group. The age of respondents at Tibet Centre traffic congested round about reveals that majority 80 $(89.0 \%)$ of the respondents were aged above 20 years. Of these a large number (44.4\%) belongs to $30-50$ years age, while $10(11.1 \%)$ were below 20 years of age group. At Empress Market area majority of the respondents 83 (80.1\%) were aged above 20 years, $(44.6 \%)$ belongs to $30-50$ years age, while $20(19.4 \%)$ were below 20 years of age group. At Garden Road commercial areas majority 46 (92\%) respondents were aged above 20 years. Of these more than half of the respondents $(56.0 \%)$ belongs to $30-50$ years age and only $(8.0 \%)$ were below 20 years of age group, while in Saddar GPO commercial area $58(86.5 \%)$ were above 20 years of age. Of these $(59.7 \%)$ of the respondents belongs to $30-50$ years age, while only $9(13.4 \%)$ were below 20 years of age group.

Figure 2 presented the $\%$ of the respondent according to the sex. Tibet Centre area comprised $66(73.3 \%)$ male and 24 $(26.7 \%)$ were female participants whose age group range between 16-55 years with the mean age of $23 \pm 5.3$ years, in Empress Market commercial area $90(87.3 \%)$ were male and $13(12.7 \%)$ were female participants range between the age 20-55 years with the mean age of $45 \pm 3.2$ years, in Garden Road area $32(64.0 \%)$ male and $18(36.0 \%)$ were female participants range between the age of $20-55$ years with the mean of $40 \pm 3.1$ years, whereas in Sadder GPO area 52 
(77.6\%) male and 15 (22.4\%) were female participants range between the age of $20-45$ years with the mean of $39 \pm 2.1$

years age limit respectively.

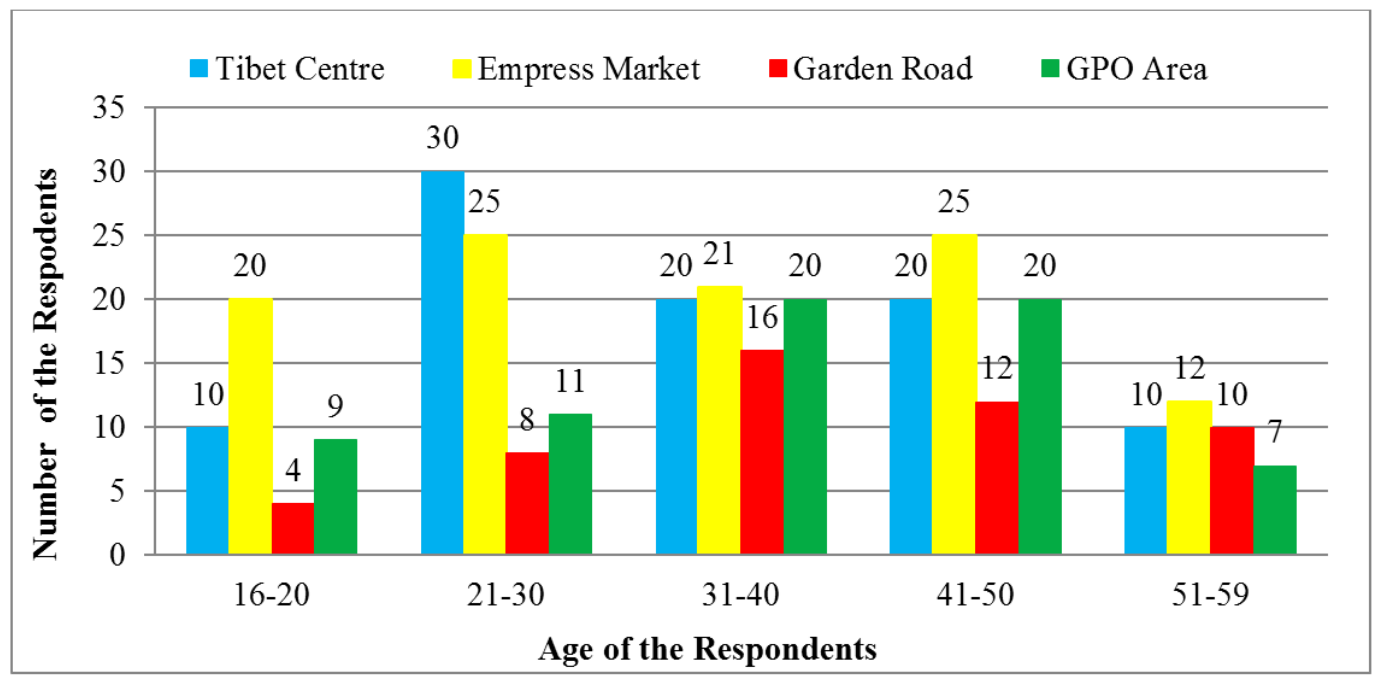

Figure 1. Respondents According to the Age group.

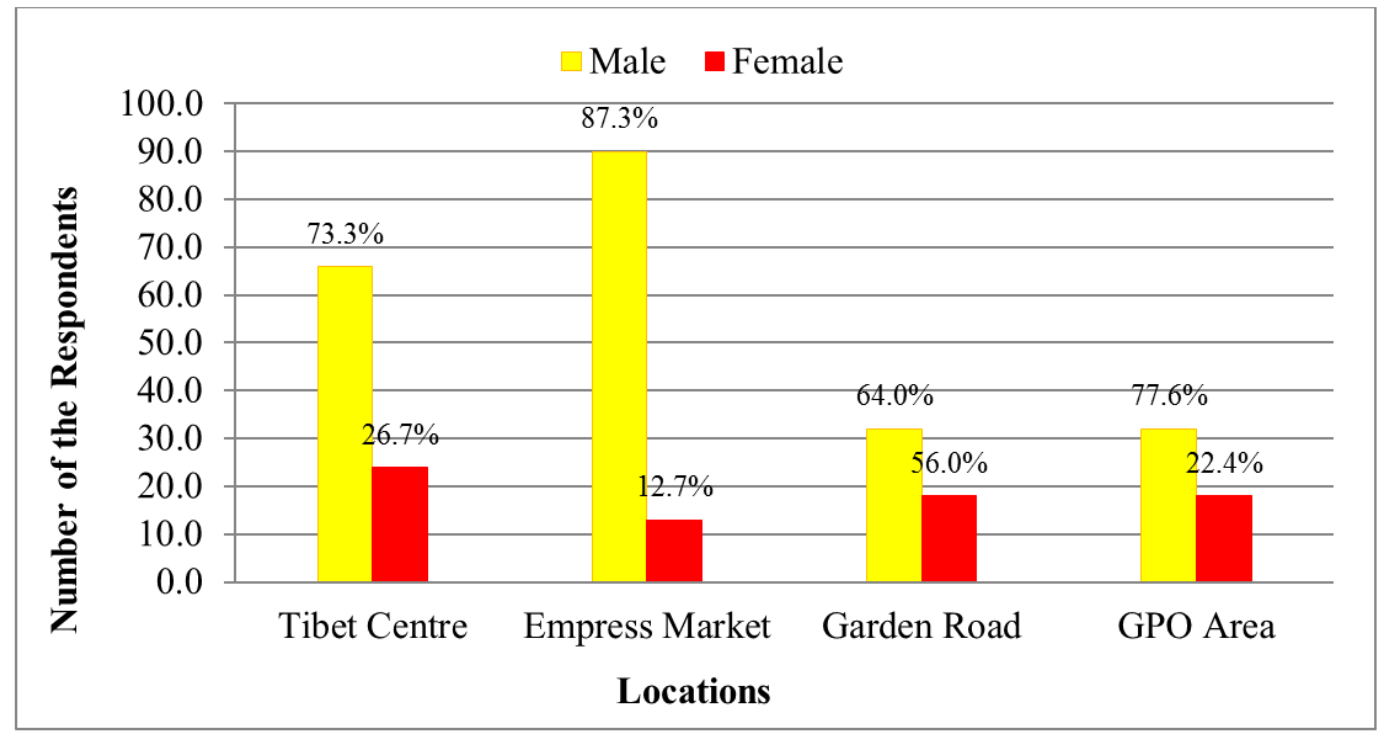

Figure 2. Respondents According to the Sex.

Figure 3 presented the percentage of the respondents according to their education level. Tibet Centre traffic congested round about reveals that $11.1 \%$ of the respondents have no education, up to secondary school certificate (level 10) educated respondents were $32.2 \%$, up to higher secondary school certificate (level 12) educated were $40 \%$ and having graduate and above level education were $16.7 \%$. In Empress Market areas $29.1 \%$ of the respondents have no education, $40 \%$ of the respondents were educated up to secondary school certificate (level 10), from remaining respondent $24.3 \%$ were educated up to higher secondary school certificate (level 12) and $12.6 \%$ were having graduate and above level education. In Garden Road commercial areas $14 \%$ of the respondents have no education, $20 \%$ of the respondents were educated up to secondary school certificate (level 10), from remaining respondent $30 \%$ were educated up to higher secondary school certificate (level 12) and majority of the respondents in this area $36 \%$ were having graduate and above level education. In Saddar GPO commercial area $18 \%$ have no education, $28 \%$ were educated up to level $10,33 \%$ educated up to level 12 , and $12.6 \%$ were having graduate and above level education.

Figure 4 presented the percentage of respondents according to the awareness / knowledge of Health Hazards associated with Portable Power Generators in home shops and workplace. More than half of the respondents 209 out of 310 (67.4\%) agreed that use of portable power generators are hazardous for human health. $223(72 \%)$ were well informed about the fact that noise pollution is a source of hearing loss, a large percentage $180(58 \%)$ indicated that portable power generator is major source of indoor noise pollution. Less than half of the respondents $94(30 \%)$ believed that noise from the use of 
portable generator can bring about conflict among neighbors, $102(33 \%)$ assumed that dispensing fuel into the portable power generator could pose any danger to human and environment. Surprisingly less than $50 \%$ of the participants $132(42 \%)$ believed that exposure to noise produced from power generators also cause sleeplessness. Majority of the respondents $223(72 \%)$ agreed that use of hearing protection device can work as a shield to protect oneself from hearing loss.

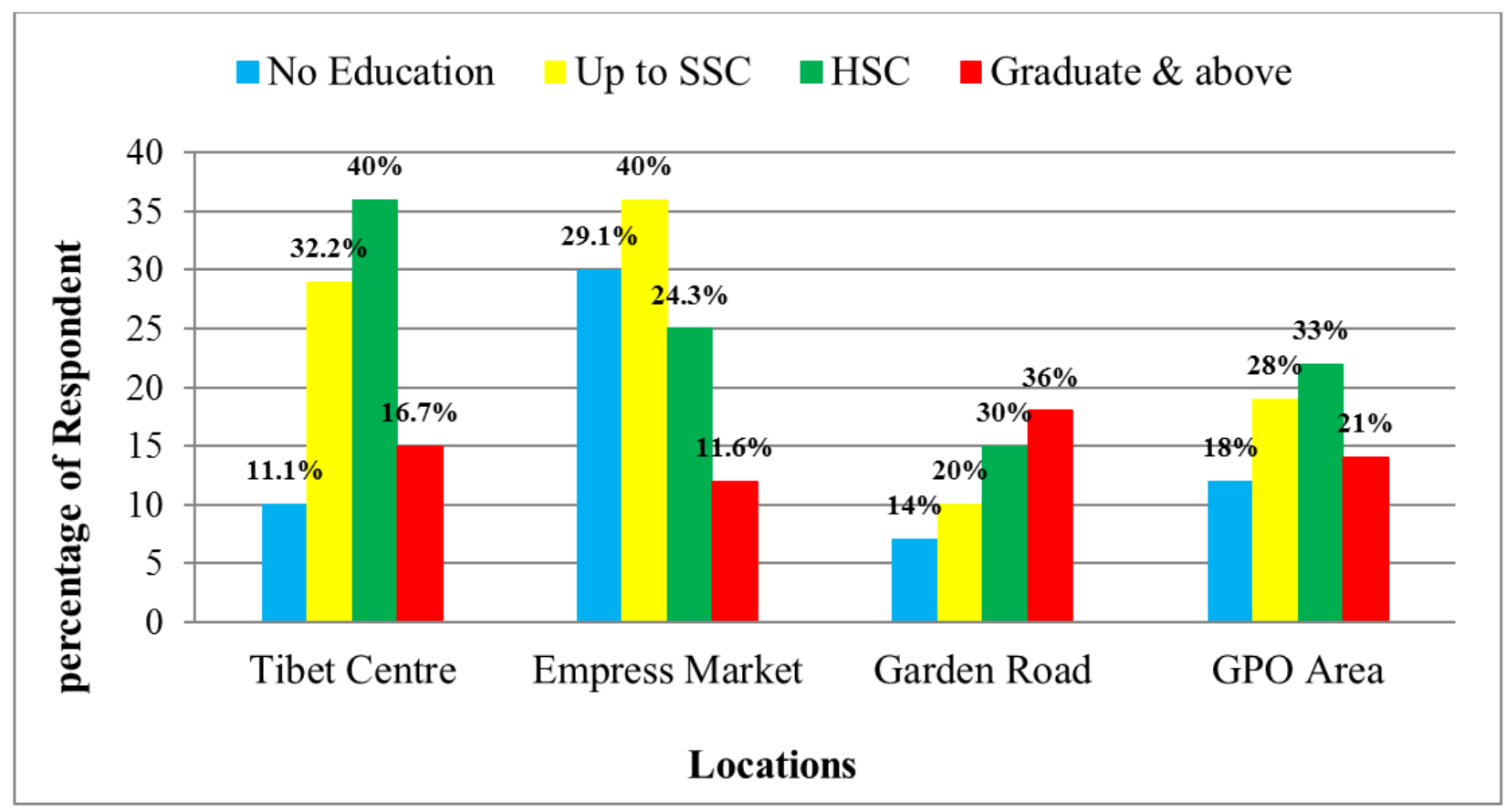

Figure 3. Respondents According to the Level of Education.

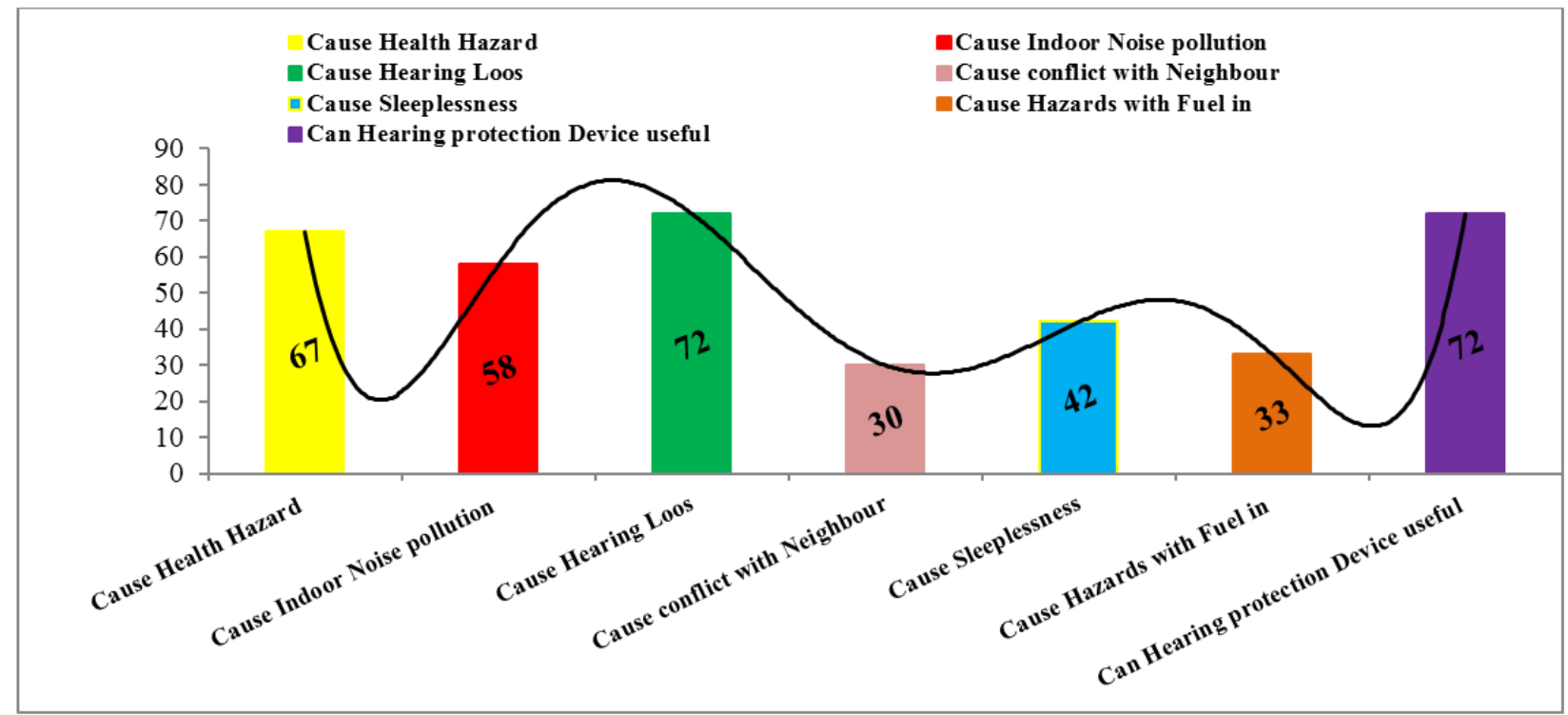

Figure 4. Percentage of Respondents according to Awareness / knowledge of Health Hazards.

Figure 5 presented the percentage of respondents according to the awareness / knowledge about health Risk with the use of Portable Power Generators. A large percentage of participants $212(68 \%)$ respond that by the indoor use of portable electric generators they feel hearing disability (especially in adults), whereas half of the respondents $162(52.3 \%)$ indicated that indoor use of portable generator shows behavioral effect specially in female as they spent most of the time in the indoor environment for house-keeping. Similarly about half respondents 146 (47\%) also complain about performance effects due to noise intensity in the indoor and outdoor environment. Less than half of the respondents $132(42 \%)$ believed that noise producing from portable generator in 
house, shops and at workplace causing hypertension problem. Similarly very low percentage of the respondents 106 (34\%) showing some mental disorder similarly 91 (29\%) complained about cardiac effects due to regular use of power generator in the indoor environment during electricity shut down period.

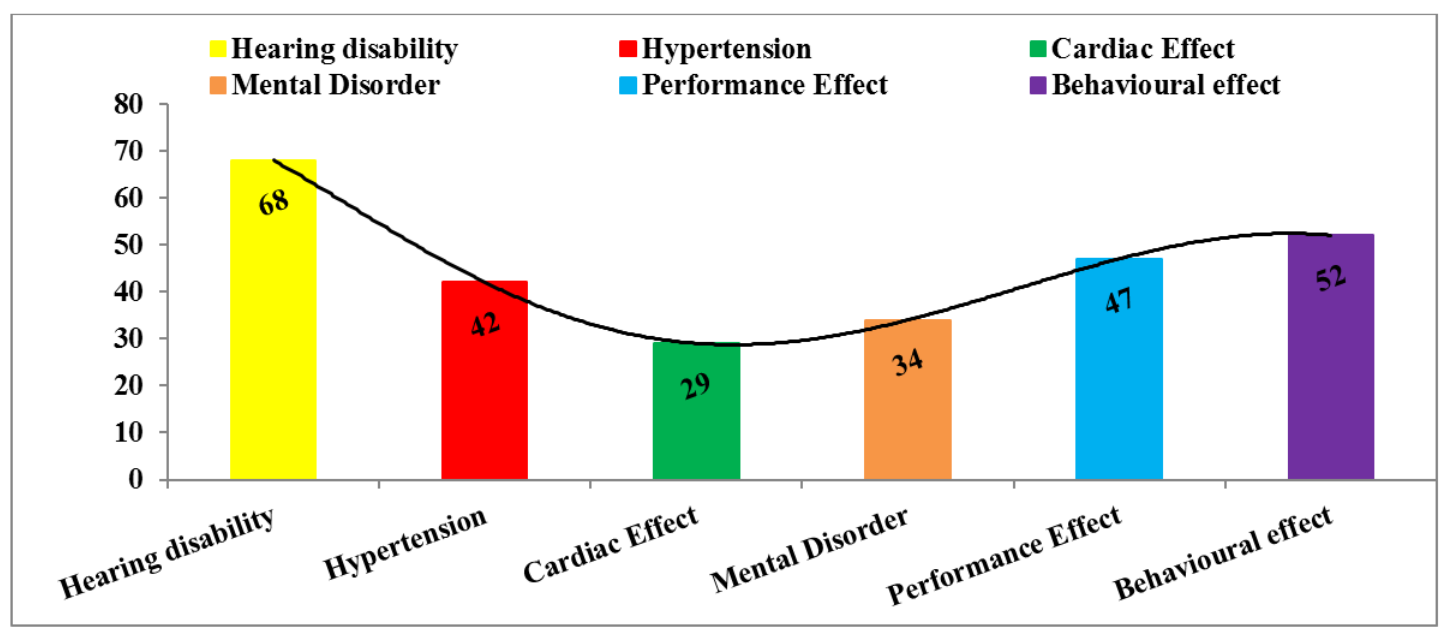

Figure 5. Percentage of Respondents according to the Risk of Health.

\section{Discussion}

Present study was conducted at 04 locations in sadder town commercial / traffic congested areas of Karachi. A planned questionnaire survey was used to collect the data about the perception and knowledge from the participants regarding the hazardous effects associated with power generator noise. The age of Participants in this study from all the selected locations ranged from 16 to 59 years. Overall majority $267(86.1 \%)$ of the respondents were above 20 years whereas $43(14 \%)$ were below 20 years of age group. Location wise age of the Respondents presented in Figure 1, Sex wise respondent presented in Figure 2, the level of education of the participants of this study presented in Figure 3 respectively. Knowledge and awareness about Health Hazards presented in Figure 4 and Figure 5 respectively. High level of Knowledge and awareness (67\%) was noticed among the users of portable power generators about health hazards. (58\%) participants respond that presently one of the major sources of noise pollution is power generators, using 03 times daily for two hours during load shedding period. According to the recent researches on noise pollution hazards majority of the respondents agreed to the fact that noise pollution is a source of hearing impairment [19]. High level of knowledge and awareness was noticed among the users of generator in all the selected commercial areas (Tibet Centre, Empress Market, Garden Road and Saddar GPO area). Result to protect themselves from hearing loss is not surprising because most of the participants were already using hearing protection devices i.e. ear plug and ear muffs to prevent from the hazards of noise pollution due to the use of power generators in the indoor environment. The efficiency of hearing protection devices mainly depend on the correct material, correct choice, proper way of using to prevent from noise pollution hazards [20]. In Nigeria a study was Steering in steel rolling mill, results show that less than $50 \%$ labors of the workers were properly using Hearing Protection Devices (HPDs), due to the lack of awareness and information regarding the noise induced health hazards [21]. Sleep disturbance is one of the serious problems due to noise pollution. Result regarding the sleep disturbance due to power generator noise is surprising, as less than $50 \%$ respondents were agreed that power generators noise is main cause of sleep disturbance. One of the reasons might that due to hard working in day / night time the noise of generator is uncountable factor than the sleep, in the view of respondent noise is bearable than the hotness of summer season. According to the World Health Organization (WHO) guideline noise level for a good sleep is $30 \mathrm{~dB}(\mathrm{~A})$, while noise levels exceeding $45 \mathrm{~dB}$ (A) should be avoided [22]. Regarding the question about conflict among neighbors, less than half of the respondents were agreed to this fact. According to the National Environment Quality Standards (NEQS), the limit for noise in residential areas was set at 55 decibels during the day and $45 \mathrm{db}$ during the night., Whereas, Diesel generators generate emit $88 \mathrm{db}$ of noise, while generators running on petrol or gas can go above $95 \mathrm{db}$ [23], None of the respondent in this study, not aware and inform about the detrimental effects of noise producing health hazards only they know about hearing impairment. Finding of this study shows that majority of the respondents revealed that noise induce hearing loose (NIHL) had low priority than other health hazards such as cancer, cardiovascular disease, pulmonary problems, chemical burn and other issues in the life. Most of the respondents regarding the loss of quality of life agreed that noise pollution is a major issue but when asked the name of major issues in terms of morbidity and mortality, NIHL shows low priority hazards than other health hazards [24]. Respondents in all the selected commercial areas showing their forceful interest to reduce the level of noise generated from portable power generators in-order to 
use this facility safely.

\section{Conclusion}

The present study shows that the Commercial areas of Karachi City are highly exposed to noise pollution. Due to shortage of electricity and erratic shutdown of power supply, inhabitants are compelled to use portable power generators in homes, offices and their work-place during shutdown period. Results show that most of the respondents had much awareness about the harmful effects of noise at workplace and home. Main finding of this study is that majority of the respondents revealed that noise induce hearing loose (NIHL) had low priority than other health hazards such as cancer, cardiovascular disease, pulmonary problems, chemical burn and other issues in the life. There is a need of Eco-City planning and of arranging awareness program on noise pollution hazards to train the workers about harmful effects of noise pollution on hearing disability, stating the level at which noise is considered hazardous. Necessary preventive measures must also be taken by the Government and appropriate authority to implement the Noise Pollution (Regulation and Control) Rules. Increased power generation is also sought to reduce the use of portable power generators and thus lower the noise pollution from this source.

\section{Novelty of the Paper}

Portable power Generators are frequently used during electricity shutdown period as an alternative temporary arrangement of electrical power supply. Most of the population are lack of education and not aware about the hazards of this device (power generators). Novelty of the paper is to aware the citizens about harmful effects of noise pollution on human health like non-auditory hazards of noise include: irritation, anger, loss of memory, sleeping disorders and mainly hearing disability.

\section{References}

[1] Debasish, P and Debasish, B. 2012. Effect of Road Traffic Noise Pollution on Human Work Efficiency in Government Offices, Private Organizations, and Commercial Business Centres in Agartala City Using Fuzzy Expert System: A Case Study. Advances in Fuzzy Systems 2012: 1-9.

[2] Azodo AP, Adejuyigbe SB. 2013. Examination of noise pollution from generators on the residents of Obantoko, Ogun State, Nigeria. Asian J. Eng. Sci. Technol. 3 (1): 31-41.

[3] Parvathi, K. and Navaneetha Gopalakrishnan A. Studies On Control Of Noise From Portable Power Generator in Martin J. Bunch, V. Madha Suresh and T. Vasantha Kumaran, eds., Proceedings of the Third International Conference on Environment and Health, Chenna i, India, 15-17 December, 2003. Chennai: Department of Geography, University of Madras and Faculty of Environmental Studies, York University. Pages 328-338.

[4] Esther O. A and Victor U. N. 2015. Impact of Noise Pollution on Human Cardiovascular System. Department of Physiology, Faculty of Basic Medical Sciences, International Journal of TROPICAL DISEASE \& Health, 6 (2): 35-43.

[5] Hiral J. J., Huma S. S, Minarva J. P, Yogesh M. G. 2017. Noise Pollution \& Human Health: A Review. Conference Paper: https://www.researchgate.net/publication/319329633).

[6] John O. O., Godson R. A., Oyewale M. M. 2016. Noise from Portable Electric Power Generators in an Institutional Setting: A Neglected Risk Factor. International Journal of Environmental Monitoring and Analysis, 4 (4): 115-120.

[7] Adefeso I., Sonibare J., Akeredolu F. and Rabiu A. 2012. Environmental Impact of Portable Power Generator on Indoor Air Quality. International Conference on Environment, Energy and Biotechnology IPCBEE vol. 33 IACSIT Press, Singapore.

[8] Awosusi A. O. and Akindutire I. O. 2014. Perceived Health Effects of Environmental Noise Pollution on the Inhabitants of Ado-Ekiti Metropolis. Ekiti State, Nigeria. Journal of Biology, Agriculture and Healthcare, 4 (26): 106-113.

[9] Ashmore M. R. and Dimitroulopoulou C. 2009. Personal exposure of children to air pollution. Atmospheric Environment, 43: 128-141.

[10] Ibitoye F. I., Adenikinju A. 2007. Future demand for electricity in Nigeria. Appl. Energy, 84 (5): 492-504.

[11] Azodo A. P. 2014. Electric power supply, main source and backing: A survey of residential utilization features. Int. J. Res. Stud. Manage, 3 (2): 87-102.

[12] Heywood J. B. (1988). Internal Combustion Engine Fundamentals. New York: McGraw Hill Inc.

[13] NIDCD Fact Sheet: Noise-Induced Hearing Loss. NIH Publication No. 97-4233. Updated (April 2007). www.nided.nih.gov.

[14] Stansfeld S., Haines M., Brown B. 2000. Noise and health in the urban environment. Rev. Environ. Health, 15: 43-82.

[15] Evans G. W., Lercher P., Meis M., Ising H., Kofler W. W. 2001. Community noise exposure and stress in children. J. Acoust. Soc. Am., 109 (3): 1023-1027.

[16] World Health Organizaiton. Deafness and Hearing Impairment Fact Sheet; 2014. Available from: http://www.who.int/mediacentre/factsheet/fs300/index.

[17] WHO. Global Estimates on Prevalence of Hearing Loss; 2012. Available http://www.who.int/pbd/deafness/WHO_GE_HL_pdf.

[18] Health Info Statistics and Epidemiology. Quick statistics, National Institute on Deafness and Other Communication Disorders (NIDCD). Available from: http://www.nidcd.nih.gov/health/statistics/pags/quick/aspx.

[19] Jibiri N. N., Olaluwoye M. O., Ayinmode B. O. 2015. Assessment of Health Effects of Noise and Vibration Levels at Major Business Complexes and Markets in Ibadan Metropolis, Nigeria. Journal of Health Science, 5 (4): 69-75.

[20] Yesufu A. L. and Ana G. R. E. E. 2012. Electric Generator Characteristics, Pattern of Use and Non Auditory Health Effects Experienced by Commercial Workers in Agbowo and Ajibode Areas of Ibadan, Nigeria. Review of Global Medicine and Healthcare Research, 3 (2). 159-171. 
[21] Ama A. A., Nwigbo S. C., Okolie P. C. and Aguh P. S. 2017. Effects of Noise and Vibration on Subjects Exposed to Electrical Power Generating Set Pollution. Advances in Research. 11 (4): 1-11.

[22] World Health Organization Regional Office for Europe, 2004. Noise and sleep. Technical meeting on sleep and health. Bonn, Germany. Retrieved $17^{\text {th }}$ May 2010 from http://w.w.w.euro.who.int/Noise/activities/20040304
[23] Published in The Express Tribune, Karachi, Pakistan on May $22^{\text {nd }}, 2011$.

[24] Federal Environmental Protection Agency (FEPA) Nigeria. 1991, Retrieved $13^{\text {th }}$ July, 2010 from www.fepanigeria.com/interimguidelines 